\title{
A family history of diabetes is associated with reduced physical fitness in the Prevalence, Prediction and Prevention of Diabetes (PPP)-Botnia study
}

\author{
B. Isomaa • B. Forsén • K. Lahti • N. Holmström • \\ J. Wadén • O. Matintupa • P. Almgren • J. G. Eriksson • \\ V. Lyssenko • M.-R. Taskinen • T. Tuomi • L. C. Groop
}

Received: 12 February 2010 / Accepted: 9 March 2010/Published online: 8 May 2010

(C) Springer-Verlag 2010

\begin{abstract}
Aims/hypothesis We studied the impact of a family history of type 2 diabetes on physical fitness, lifestyle factors and diabetes-related metabolic factors.

Methods The Prevalence, Prediction and Prevention of Diabetes (PPP)-Botnia study is a population-based study in Western Finland, which includes a random sample of 5,208 individuals aged 18 to 75 years identified through the national Finnish Population Registry. Physical activity, dietary habits and family history of type 2 diabetes were assessed by questionnaires and physical fitness by a
\end{abstract}

Electronic supplementary material The online version of this article (doi:10.1007/s00125-010-1776-y) contains supplementary material,

which is available to authorised users.

B. Isomaa $\cdot \mathrm{J}$. Wadén $\cdot$ O. Matintupa $\cdot$ T. Tuomi

Folkhälsan Genetic Institute,

Helsinki, Finland

B. Isomaa $(\bowtie)$

Department of Social Services and Health Care,

PB 111, 68601 Jakobstad, Finland

e-mail: bo.isoma@folkhalsan.fi

B. Forsén

Närpes Health Care Center,

Närpes, Finland

K. Lahti $\cdot$ J. G. Eriksson

Vasa Central Hospital, Vasa, Finland

N. Holmström

Korsholm Health Care Center, Korsholm, Finland

P. Almgren • V. Lyssenko • L. C. Groop

Department of Clinical Sciences-Diabetes and Endocrinology,

Clinical Research Center, Lund University, Malmö University Hospital,

Malmö, Sweden validated $2 \mathrm{~km}$ walking test. Insulin secretion and action were assessed based upon OGTT measurements of insulin and glucose.

Results A family history of type 2 diabetes was associated with a 2.4-fold risk of diabetes and lower physical fitness (maximal aerobic capacity $29.2 \pm 7.2$ vs $32.1 \pm 7.0, p=0.01$ ) despite having similar reported physical activity to that of individuals with no family history. The same individuals also had reduced insulin secretion adjusted for insulin resistance, i.e. disposition index $(p<0.001)$ despite having higher BMI (27.4 \pm 4.6 vs $\left.26.0 \pm 4.3 \mathrm{~kg} / \mathrm{m}^{2}, p<0.001\right)$.
J. G. Eriksson

Department of Public Health, Helsinki University,

Helsinki, Finland

M.-R. Taskinen

Department of Internal Medicine,

Division of Cardiology,

Helsinki University Central Hospital,

Helsinki, Finland

T. Tuomi

Department of Medicine,

Helsinki University Central Hospital,

Helsinki, Finland

T. Tuomi

Research Program for Molecular Medicine,

University of Helsinki,

Helsinki, Finland

J. G. Eriksson

National Institute for Health and Welfare,

Helsinki, Finland 
Conclusions/interpretation Individuals with a family history of type 2 diabetes are characterised by lower physical fitness, which cannot solely be explained by lower physical activity. They also have an impaired capacity of beta cells to compensate for an increase in insulin resistance imposed by an increase in BMI. These defects should be important targets for interventions aiming at preventing type 2 diabetes in individuals with inherited susceptibility to the disease.

Keywords Family history of diabetes · Insulin secretion and action · Physical activity · Physical fitness · Prevalence

$\begin{array}{ll}\text { Abbreviations } & \\ \text { CIR } & \text { Corrected insulin response } \\ \text { FH+ } & \text { Positive for family history of diabetes } \\ \text { FH- } & \text { Negative for family history of diabetes } \\ \text { HOMA-IR } & \text { HOMA of insulin resistance } \\ \text { IFG } & \text { Impaired fasting glucose } \\ \text { IGT } & \text { Impaired glucose tolerance } \\ \text { ISI } & \text { Insulin sensitivity index } \\ \text { MET } & \text { Metabolic equivalent } \\ \text { PPP } & \text { Prevalence, Prediction and Prevention } \\ & \text { of Diabetes } \\ \dot{V} \mathrm{O}_{2} & \text { Maximal aerobic capacity }\end{array}$

\section{Introduction}

A family history of diabetes is a strong risk factor for type 2 diabetes [1] with a familial risk estimated to about 3.0 [2]. However, this information is usually obtained from familybased studies, which may overestimate the true effect of family history in the population. Several studies have shown that individuals with a family history of type 2 diabetes are characterised by insulin resistance [3], but patients with a family history of type 2 diabetes also tend to be more obese and sedentary. It has therefore not been easy to distinguish whether insulin resistance is a consequence of a sedentary lifestyle or an inherited defect.

To address these issues, we assessed the influence of a family history of type 2 diabetes on insulin secretion and action, taking into account physical activity and physical fitness.

\section{Methods}

The Prevalence, Prediction and Prevention of diabetes (PPP)-Botnia Study is a population-based study in Western Finland carried out from 2004 to 2008 to obtain accurate estimates of prevalence and risk factors for type 2 diabetes, impaired glucose tolerance (IGT), impaired fasting glucose
(IFG) and the metabolic syndrome in the adult population and to use this information for prediction and prevention of the disease. The participants were randomly recruited from the national Finnish Population Registry to represent 6 to $7 \%$ of the population in the 18 - to 75 -year age range. Altogether 5,208 individuals (Electronic supplementary material $[E S M]$ Table 1) participated in the study $(54.7 \%$ of those invited). The participants gave their written informed consent and the study protocol was approved by the Ethics Committee of Helsinki University Hospital, Finland.

Body weight, height, waist circumference and blood pressure were measured. Participants were asked whether they had diabetes and other diseases, as well as about any medication taken. They were also asked whether they were positive for family history of diabetes $(\mathrm{FH}+)$, defined as known diabetes in at least one first-degree relative. Data on whether participants had a family history of diabetes could be reliably assessed in $89.0 \%$ of the male and in $91.1 \%$ of the female participants $(n=4,693)$. They participated in a $75 \mathrm{~g}$ OGTT after a $12 \mathrm{~h}$ overnight fast, unless they had known diabetes and were on glucose-lowering medication, or had fasting plasma glucose $>10 \mathrm{mmol} / \mathrm{l}$. Samples for glucose and insulin were drawn at 0,30 and $120 \mathrm{~min}$, and for total cholesterol, HDL-cholesterol and triacylglycerol at 0 min. Diagnosis of diabetes was based on the OGTT or a history of previously known diabetes applying WHO criteria. In uncertain cases, the diagnosis was confirmed from patient records. Altogether, 327 participants (6.3\%) had diabetes, 354 participants (6.8\%) IGT and 416 participants (8.0\%) IFG.

The corrected insulin response $(\mathrm{CIR})$, i.e. $(100 \times$ insulin $[\mathrm{pmol} / \mathrm{l}]$ at $30 \mathrm{~min}) /($ glucose $[\mathrm{mmol} / 1]$ at $30 \mathrm{~min}) \times($ glucose [mmol/l] at $30 \mathrm{~min}-3.89 \mathrm{mmol} / \mathrm{l})$, was used as measure of insulin secretion [4]. Both HOMA of insulin resistance (HOMA-IR), calculated from fasting glucose and insulin concentrations [5], and the insulin sensitivity index (ISI), i.e. $\mathrm{ISI}=10,000 / \sqrt{ }$ (fasting plasma glucose $[\mathrm{mmol} / \mathrm{l}] \times$ fasting insulin $[\mathrm{pmol} / 1]) \times($ mean OGTT glucose $[\mathrm{mmol} / \mathrm{l}] \times$ mean OGTT [pmol/1] insulin), were used to estimate insulin sensitivity. The disposition index $(\mathrm{DI}=\mathrm{CIR} \times \mathrm{ISI})$ was used to measure insulin secretion adjusted for the degree of insulin sensitivity [6].

Plasma glucose was measured with a glucose dehydrogenase method (Hemocue, Angelholm, Sweden), serum insulin by fluoroimmunometric assay (Delfia, Perkin Elmer, Turku, Finland) and lipid concentrations with an enzymatic method (Konelab 60i analyser; Thermo Electron Oy, Vantaa, Finland). LDL-cholesterol concentration was calculated.

Frequency and intensity of current physical activity and physical activity during the past 12 months was assessed using the validated Kuopio Ischemic Heart Disease Questionnaire [7]. It provides detailed information on common 
lifestyle, commuting and leisure-time physical activity and enables assessment of total physical activity as metabolic equivalent $(M E T) h$ per week $(M E T \times h /$ week). Based upon leisure-time activity, participants were defined as moderately active, if they performed $>30$ min physical activity three or more times per week with an intensity resulting in breathlessness and/or sweating.

Physical fitness was assessed by a $2 \mathrm{~km}$ walking test, which has been validated up to the age of 65 years [8] and provides an indirect estimate of oxygen uptake. Based upon walking time and heart rate at the end of the test, maximal aerobic capacity $\left(\dot{V} \mathrm{O}_{2} \max \right)\left(\mathrm{ml} \mathrm{min}{ }^{-1} \mathrm{~kg}^{-1}\right)$, adjusted for age, sex and BMI, was calculated. A prerequisite for participating in the $2 \mathrm{~km}$ walking test is the ability to walk briskly achieving a heart rate $\geq 70 \%$ of age-related maximal heart rate. Contraindications were activity-related angina or dyspnoea, uncontrolled hypertension, or musculoskeletal symptoms preventing brisk walking. Users of beta-blockers were excluded. Altogether, 1,681 participants (40.7\%) aged 18 to 65 years performed an adequate walking test $(29.6 \%$ did not want to participate, $11.9 \%$ had contraindications, $0.2 \%$ did not complete the test and $17.6 \%$ did not fulfil the criteria for heart rate at the end of the test).

A frequency-based questionnaire included questions about common dietary components to calculate an index of healthy food habits [9]. Food habits were regarded as healthy if two of the following criteria were fulfilled: (1) daily consumption of vegetables; (2) consumption of low-fat milk; and (3) use of vegetable margarine or no fat on bread.

The data are expressed as mean $\pm \mathrm{SD}$ or percentages. The difference between group means was tested with $t$ test and between-group frequencies with $\chi^{2}$ or Fischer's exact test. Variables not normally distributed were transformed logarithmically before analysis. When appropriate, the data were analysed by linear regression analysis, adjusted for age and BMI. The risk of diabetes, IGT or IFG was tested with multiple logistic regression analysis using SPSS 12.0 for Windows (SPSS, Chicago, IL, USA). A $p$ value of $p<$ 0.05 was considered statistically significant.

\section{Results}

An $\mathrm{FH}+$ status was more common among females than males $(36.3 \%$ vs $30.5 \%, p<0.001)$ (ESM Table 1$)$. FH+ individuals were older, and had higher BMI and a greater waist circumference than individuals who were negative for family history of diabetes $\left(\mathrm{FH}^{-}\right)$. They also had a higher prevalence of IGT, IFG and the metabolic syndrome. After adjustment for age, BMI and sex, a family history of type 2 diabetes was associated with a 2.4-fold risk of type 2 diabetes $(p<0.001)$, a 1.3 -fold risk of IFG $(p=0.03)$ and a 1.4-fold risk of IGT $(p=0.01)$ (ESM Table 2). A family history of type 2 diabetes was associated with reduced beta cell function expressed as CIR to oral glucose $(p<0.001)$. $\mathrm{FH}+$ individuals also showed a modest reduction in ISI or increased insulin resistance compared with $\mathrm{FH}$ - individuals $(p=0.02)$. Therefore, adjustment of insulin secretion for the degree of insulin resistance (disposition index) resulted in an even greater difference between $\mathrm{FH}+$ and $\mathrm{FH}-$ individuals (Table 1). If restricted to individuals with normal glucose tolerance $(n=3,814)$, the difference in ISI disappeared, whereas the difference in disposition index between $\mathrm{FH}+$ and $\mathrm{FH}-$ individuals remained significant (ESM Table 3). If restricted to individuals with IGT and/or IFG $(n=599)$, no significant differences were seen between $\mathrm{FH}+$ and $\mathrm{FH}-$ individuals (ESM Table 4).

Physical fitness, assessed as $\dot{V} \mathrm{O}_{2}$ max from the walking test and adjusted for differences in age and BMI, was significantly lower in $\mathrm{FH}+$ participants than in $\mathrm{FH}-$ participants $(29.1 \pm 7.2$ vs $32.0 \pm 7.0, p=0.01)$ (Table 1$)$. In a linear regression analysis the differences in estimated $\dot{V} \mathrm{O}_{2}$ max could not be explained by differences in age, sex or BMI (data not shown). Interestingly, this difference could not be explained by differences in reported physical activity (MET $\times$ h/week $31.5 \pm 28.7$ vs $30.9 \pm 27.9, p=0.5)$.

\section{Discussion}

In this population-based study from Western Finland a family history of type 2 diabetes was associated with abdominal fat accumulation, higher BMI, slight increase in insulin resistance, reduced physical fitness and a reduction in beta cell function adjusted both for level of glycaemia and insulin resistance. $\mathrm{FH}+$ status was also associated with a 2.4-fold risk of type 2 diabetes, a 1.4-fold risk of IGT and a 1.3-fold risk of IFG. These figures are similar to those reported in the family-based Botnia Study [10], as well as in other studies [2]. The risk of type 2 diabetes increased to 2.7 (CI 95\% 1.5-4.8) if both parents had the disease and to 2.5 (CI 95\% 1.9-34) if a sibling had type 2 diabetes, giving a sibling-relative risk close to the values derived from family-based studies (data not shown).

The most compelling finding was that a family history of type 2 diabetes was associated with reduced physical fitness. Poor physical fitness has been claimed to reflect differences in lifestyle, but we observed no differences in physical activity between $\mathrm{FH}+$ and $\mathrm{FH}-$ individuals. If anything, FH + individuals had adopted healthier food habits than $\mathrm{FH}-$ participants. In support of our findings, Thamer et al. also showed in a study of young healthy individuals that a family history of diabetes was associated with lower oxygen uptake [11].

The influence of a family history of type 2 diabetes on energy metabolism does not seem to be restricted to 
Table 1 Clinical characteristics and lifestyle in 4,693 individuals in relation to family history of type 2 diabetes

${ }^{\mathrm{a}}$ Unadjusted; ${ }^{\mathrm{b}}$ adjusted for age, BMI and sex

${ }^{\mathrm{c}}{ }_{n=1,186 / 524}$

\begin{tabular}{|c|c|c|c|c|}
\hline Characteristics & $\mathrm{FH}^{-}$ & $\mathrm{FH}+$ & $p$ value $^{\mathrm{a}}$ & $p$ value ${ }^{\mathrm{b}}$ \\
\hline$n$ & 3,114 & 1,579 & & \\
\hline Age (years) & $46.4 \pm 15.9$ & $54.4 \pm 13.6$ & $<0.001$ & \\
\hline Male sex $(\%)$ & 48.6 & 42.0 & $<0.001$ & \\
\hline BMI $\left(\mathrm{kg} / \mathrm{m}^{2}\right)$ & $26.0 \pm 4.3$ & $27.4 \pm 4.6$ & $<0.001$ & \\
\hline Waist (cm) & $87.9 \pm 13.1$ & $91.7 \pm 13.1$ & $<0.001$ & 0.02 \\
\hline Cholesterol (mmol/l) & $5.2 \pm 1.0$ & $5.4 \pm 1.1$ & $<0.001$ & 0.15 \\
\hline HDL-cholesterol (mmol/l) & $1.41 \pm 0.39$ & $1.38 \pm 0.40$ & 0.02 & 0.02 \\
\hline Triacylglycerol (mmol/l) & $1.3 \pm 0.8$ & $1.4 \pm 0.8$ & $<0.001$ & 0.8 \\
\hline LDL-cholesterol (mmol/l) & $3.3 \pm 0.9$ & $3.4 \pm 1.0$ & $<0.001$ & 0.4 \\
\hline Systolic BP & $131.5 \pm 18.6$ & $137.1 \pm 20.0$ & $<0.001$ & 0.2 \\
\hline Diastolic BP & $79.9 \pm 10.2$ & $81.6 \pm 9.7$ & $<0.001$ & 0.5 \\
\hline Metabolic syndrome (\%) & 16.6 & 28.9 & $<0.001$ & 0.001 \\
\hline HOMA-IR & $9.8 \pm 10.6$ & $12.3 \pm 19.1$ & $<0.001$ & 0.01 \\
\hline ISI & $28.0 \pm 16.8$ & $25.0 \pm 16.8$ & $<0.001$ & 0.02 \\
\hline CIR & $1,199.2 \pm 1,105.6$ & $1,034.1 \pm 1,059.4$ & $<0.001$ & $<0.001$ \\
\hline Disposition index & $30,291 \pm 31,822$ & $23,831 \pm 31,014$ & $<0.001$ & $<0.001$ \\
\hline Estimated $\dot{V} \mathrm{O}_{2} \max \left(\mathrm{ml} \mathrm{min}{ }^{-1} \mathrm{~kg}^{-1}\right)^{\mathrm{c}}$ & $32.1 \pm 7.0$ & $29.2 \pm 7.2$ & $<0.001$ & 0.01 \\
\hline Physical activity $(\mathrm{MET} \times \mathrm{h} /$ week $)$ & $31.5 \pm 28.7$ & $30.9 \pm 27.9$ & 0.8 & 0.9 \\
\hline Regular, moderate physical activity (\%) & 42.4 & 45.0 & 0.25 & 0.14 \\
\hline Healthy food habits $(\%)$ & 65.3 & 74.3 & $<0.001$ & 0.002 \\
\hline
\end{tabular}

maximal oxygen uptake, as we have previously observed decreased energy expenditure in the basal state and after a euglycaemic-hyperinsulinaemic clamp in $\mathrm{FH}+$ compared with $\mathrm{FH}^{-}$participants [1]. There are several potential explanations for these findings. Several studies have reported decreased expression of genes regulating oxidative phosphorylation in patients with type 2 diabetes and their first-degree relatives [12]. It has been debated whether this is a primary inherited or an acquired phenomenon. The present study would support the former view. However, some caveats of our study should be underlined. The walking test, for example, provides an indirect measure of oxygen uptake [8] and data could be used from only $41 \%$ of the participants aged 18 to 65 years.

Another central finding was that after adjusting for age, BMI, glucose tolerance and degree of insulin sensitivity, $\mathrm{FH}+$ individuals had impaired beta cell function compared with $\mathrm{FH}^{-}$individuals. This is in keeping with the strong predictive effect of an impaired disposition index on risk of type 2 diabetes [10]. In contrast to several previous studies [13] including our own [1], we observed only small differences in insulin sensitivity between $\mathrm{FH}+$ and $\mathrm{FH}^{-}$ individuals. A potential source of error could be the use of crude estimates of insulin sensitivity instead of the euglycaemic-hyperinsulinaemic clamp, which we had used previously. In previous studies, on the other hand, matching for BMI may not have been perfect, with even very large studies like the EGIR only able to demonstrate minor differences in insulin sensitivity between $\mathrm{FH}+$ and $\mathrm{FH}-$ individuals [13].

The central role of beta cell dysfunction in the pathogenesis of type 2 diabetes was underscored in recent whole-genome association studies, which almost exclusively identified variants in genes with potential effects on beta cell function as being associated with type 2 diabetes [14]. A defect in the capacity of beta cells to cope with the increased needs imposed by increasing body weight and insulin resistance seems to be inevitable in the progression towards manifest type 2 diabetes.

In conclusion, a family history of type 2 diabetes not only predisposes to obesity, but also to poor physical fitness and impaired capacity of beta cells to compensate for the increased insulin needs imposed by an increase in BMI.

Acknowledgements The PPP-Botnia study has been financially supported by grants from the Sigrid Juselius Foundation, Folkhälsan Research Foundation, Nordic Center of Excellence in Disease Genetics, an EU grant (EXGENESIS), Signe and Ane Gyllenberg Foundation, Swedish Cultural Foundation in Finland, Finnish Diabetes Research Foundation, Foundation for Life and Health in Finland, Finnish Medical Society, Paavo Nurmi Foundation, Helsinki University Central Hospital Research Foundation, Perklén Foundation, Ollqvist Foundation and Närpes Health Care Foundation. The study has also been supported by the Municipal Heath Care Center and Hospital in Jakobstad and Health Care Centers in Vasa, Närpes and Korsholm. The skilful assistance of the Botnia Study Group is gratefully acknowledged.

Duality of interest The authors declare that there is no duality of interest associated with this manuscript. 


\section{References}

1. Groop L, Forsblom C, Lehtovirta M et al (1996) Metabolic consequences of a family history of NIDDM (the Botnia study): evidence for sex-specific parental effects. Diabetes 45:1585-1593

2. Valdez R, Yoon PW, Liu T, Khoury MJ (2007) Family history and prevalence of diabetes in the U.S. population: the 6-year results from the National Health and Nutrition Examination Survey (1999-2004). Diab Care 30:2517-2522

3. Eriksson J, Franssila-Kallunki A, Ekstrand A et al (1989) Early metabolic defects in persons at increased risk for non-insulindependent diabetes mellitus. N Engl J Med 321:337-343

4. Hanson RL, Pratley RE, Bogardus C et al (2000) Evaluation of simple indices of insulin sensitivity and secretion for use in epidemiologic studies. Am J Epidemiol 151:190-198

5. Matthews DR, Hosker JP, Rudenski A, Turner RC (1985) Homeostatic model assessment (HOMA). Measurement of insulin resistance and beta-cell deficit in man. Diabetologia 28:412-419

6. Matsuda M, DeFronzo RA (1999) Insulin sensitivity indices obtained from oral glucose tolerance testing: comparison with the euglycemic insulin clamp. Diab Care 22:1462-1470

7. Salonen JT, Lakka TA (1987) Assessment of physical activity in population studies - validity and consistency of the methods in the Kuopio Ischemic Heart Disease Risk Factor Study. Scand J Sports Sci 9:89-95
8. Oja P, Laukkanen R, Pasanen M, Tyry T, Vuori I (1991) A 2-km walking test for assessing the cardiorespiratory fitness of healthy adults. Int J Sports Med 12:356-362

9. Helakorpi S, Patja K, Prättälä R, Uutela A (2007) Health behaviour and health among the Finnish adult population, Spring 2006. Publications of the National Public Health Institute. Available from www.thl.fi/thl-client/pdfs/dcb684e6-d94f-4724-96d1-9f382492ac54, accessed 15 April 2010 (abstract available in English)

10. Lyssenko V, Almgren P, Anevski D et al (2005) Predictors of and longitudinal changes in insulin sensitivity and secretion preceding onset of type 2 diabetes. Diabetes 54:166-174

11. Thamer C, Stumvoll M, Niess A et al (2003) Reduced skeletal muscle oxygen uptake and reduced beta-cell function: two early abnormalities in normal glucose-tolerant offspring of patients with type 2 diabetes. Diab Care 26:2126-2132

12. Befroy DE, Petersen KF, Dufour S et al (2007) Impaired mitochondrial substrate oxidation in muscle of insulin-resistant offspring of type 2 diabetic patients. Diabetes 56:1367-1381

13. Waag A, Lehtovirta M, Thye-Ronn P, Groop L (2001) European group of insulin resistance: metabolic impact of a family history of type 2 diabetes. Results from a European multicentre study (EGIR). Diabet Med 18:533-540

14. Zeggini E, Scott LJ, Saxena R et al (2008) Meta-analysis of genome-wide association data and large-scale replication identifies several additional susceptibility loci for type 2 diabetes. Nat Genet 40:638-645 